\title{
Concepções sobre autonomia em faixas etárias diversas
}

\author{
Conceptions of autonomy in \\ different age groups
}

\author{
Maria Lucia SEIDL-DE-MOURA \\ Luciana Fontes PESSÔA ${ }^{2}$ \\ Deise Maria Leal Fernandes MENDES ${ }^{3}$ \\ Dandara de Oliveira RAMOS ${ }^{4}$ \\ Ana Carolina Monerat FIORAVANTI-BASTOS ${ }^{5}$ \\ Rafael Vera Cruz de CARVALHO ${ }^{6}$ \\ Luciana BROOKING 6 \\ Tânia Abreu da Silva VICTOR ${ }^{6}$
}

\section{Resumo}

Autonomia e relação são tendências universais desenvolvidas ao longo da ontogênese, concomitantes com distintas fases psicossociais. A autonomia é compreendida como uma necessidade psicológica que não exclui a de relação com os outros e proximidade interpessoal. Assim, o objetivo deste estudo foi analisar as crenças e concepções sobre autonomia em diferentes faixas etárias. Participaram 110 sujeitos, dentre eles crianças de 10 a 13 anos de idade; adolescentes entre 15 e 18 anos; jovens e adultos entre 20 e 50 anos; e adultos acima dos 50 . Os participantes responderam um questionário de dados sociodemográficos e à questão de evocação de palavras ou expressões relacionadas a autonomia. Utilizando a análise de conteúdo temático-categorial, foram estabelecidas dez categorias, e as respostas foram classificadas de acordo com elas. Diferenças entre as faixas etárias foram encontradas, sendo que as categorias independência e senso de liberdade foram as mais frequentes. Os resultados sugerem o desenvolvimento de um processo contínuo com a construção da identidade se dando ao longo do ciclo vital.

Palavras-chave: Autonomia; Crenças (não religiosas); Desenvolvimento humano; Grupos etários.

$\nabla \nabla \nabla \nabla$

1 Universidade do Estado do Rio de Janeiro, Instituto de Psicologia, Grupo de Pesquisa Interação Social e Desenvolvimento. R. São Francisco Xavier, 524, Maracanã, 20550-900, Rio de Janeiro, RJ, Brasil. Correspondência para/Correspondence to: M.L. SEIDL-DE-MOURA. E-mail: <mlseidl@gmail.com>.

2 Pontifícia Universidade Católica do Rio de Janeiro, Departamento de Psicologia, Curso de Psicologia. Rio de Janeiro, RJ, Brasil.

${ }^{3}$ Universidade do Estado do Rio de Janeiro, Instituto de Psicologia, Grupo de Pesquisa Interação Social e Desenvolvimento. Rio de Janeiro, RJ, Brasil.

${ }^{4}$ Universidade do Estado do Rio de Janeiro, Instituto de Medicina Social, Programa de Pós-Graduação em Saúde Coletiva. Rio de Janeiro, RJ, Brasil.

5 Universidade Federal Fluminense, Departamento de Psicologia, Grupo de Pesquisa Interação Social e Desenvolvimento. Rio de Janeiro, RJ, Brasil.

${ }^{6}$ Universidade do Estado do Rio de Janeiro, Instituto de Psicologia, Programa de Pós-Graduação em Psicologia Social. Rio de Janeiro, RJ, Brasil. 


\begin{abstract}
Autonomy and relatedness are universal tendencies developed during ontogenesis in parallel with distinct psychosocial stages. Autonomy is understood as a psychological need that includes relatedness and proximity to others. The aim of the present study was to analyze the beliefs and ideas about autonomy in different age groups. A total of 110 subjects participated in this study: 10-13yo children; 15-18yo adolescents; 20-50yo adults; over 50yo adults. Participants answered a socio-demographic questionnaire and a question about evocation of words or phrases related to autonomy. Using Thematic-Categorical Content Analysis, ten categories were proposed, and the answers were classified according to them. Differences between age groups were found, and the categories denominated Independency and Sense of Freedom were the most frequent. The results suggest the development of a continuous process with identity construction occurring throughout the life cycle.
\end{abstract}

Keywords: Autonomy; Human development; Beliefs (nonreligious); Age groups.

Autonomia e seu desenvolvimento têm recebido destaque em teorias psicológicas. A perspectiva psicanalítica, segundo alguns autores (Greenfield, Keller, Fuligni, \& Maynard, 2003), tem enfatizado autonomia, separação e independência como os alvos do desenvolvimento, em especial, após o inicio da escolarização, e a consequente demanda por demonstrações de comportamentos autorregulatórios (Moura \& Gabassi, 1998) na adolescência. No entanto, Greenfield et al. (2003), Kagitçibasi (2012) e Keller (2012) levam em conta a variabilidade que o conceito de "desenvolvimento sadio" pode assumir em diferentes culturas.

Segundo Carvalho, Seidl-de-Moura, Martins, e Vieira (2014), autonomia e relação são tendências universais desenvolvidas na ontogênese. A espécie humana possui uma organização complexa e a relação com seus coespecíficos é essencial para sua sobrevivência tanto física quanto psicológica (Seidl-de-Moura \& Ribas, 2009). Saber agir sobre o ambiente e saber se relacionar com os outros são capacidades adaptativas que garantem a aptidão dos indivíduos. Desafios ou ameaças a essas necessidades psicossociais desencadeiam esforços de manutenção ou reparação das mesmas, o que é conhecido como o processo de coping ou enfrentamento (Ramos, Enumo, \& Paula, 2015). No entanto, a forma como essas tendências se manifestam varia em função do ambiente físico e do contexto sociocultural.

Para compreender a dinâmica do desenvolvimento dessas duas necessidades humanas em diversos contextos culturais, algumas concepções teóricas têm sido formuladas. Greenfield et al.
(2003) reviram a literatura na área, usando como eixo de organização as tarefas universais de desenvolvimento: formação de relacionamentos, aquisição de conhecimento e equilíbrio entre autonomia/relação. Para as autoras, essas tarefas são relevantes em momentos diversos da ontogênese, sendo a primeira desde o nascimento, a segunda na infância inicial e a terceira na adolescência. Embora se possa concordar com a importância relativa assumida por cada tarefa nesses momentos, pode-se pensar que são construídas ao longo de todo o ciclo vital. O ser humano estabelece relações, constrói conhecimento e desenvolve um self, ou seja, a noção de si, sendo que a autonomia e a relação são diferentemente valorizadas ao longo da vida e de acordo com o contexto cultural e o momento histórico vividos.

Algumas das principais contribuições teóricas sobre o desenvolvimento da autonomia e da relação são discutidas em Carvalho et al. (2014). No texto, são apresentados os modelos de três autoras: Kagitçibasi, Keller e Greenfield. A primeira (Kagitçibasi, 2007) apresenta um modelo bidimensional com os eixos de agência e distância interpessoal. A agência envolve o quanto o indivíduo é autônomo em suas decisões e ações, variando em um continuum, de um polo de autonomia (agir por conta própria) a um polo de heteronomia (agir em concordância com a opinião dos outros). O continuum da distância interpessoal, por sua vez, remete à proximidade no relacionamento com os outros, variando de um polo com alto grau de proximidade a outro com alto grau de separação. 
Um dos conceitos importantes nessas visões teóricas é o de autonomia relacionada, proposto por Kagitçibasi (1996) e adotado por outros autores, como pode ser observado na revisão de Seidl-de-Moura, Carvalho e Vieira (2013). Para Keller (2012), esse é um modelo híbrido de desenvolvimento do self. Nele, há uma ênfase na autonomia psicológica, mas também existe a importância da família como uma unidade social, com uma visão de relação psicológica predominante. A autonomia é compreendida como uma necessidade psicológica, mas sem desvalorização de relacionamentos. Para Kagitçibasi (2012), é a combinação do polo de autonomia (no eixo de agência) e de proximidade (no de distância interpessoal) que representa um modelo saudável por equilibrar as duas tarefas universais de desenvolvimento.

A partir do interesse pela dinâmica do desenvolvimento da autonomia e da relação/interdependência em contextos brasileiros, um conjunto de estudos tem sido desenvolvido (para uma revisão, vide Seidl-de-Moura et al., 2013) no país. Esses estudos indicam a prevalência de uma trajetória de desenvolvimento caracterizada pela valorização da autonomia e, ao mesmo tempo, da proximidade interpessoal, ou seja, coincidindo com o modelo da autonomia relacionada. Isso foi observado em metas de socialização e práticas parentais, na fala de mães com seus bebês, no desempenho das crianças em tarefas de autorregulação e autorreconhecimento, na valorização de sistemas parentais (descritos por Keller, 2007) por mães, avós, babás e professoras de creche. Também foi observada, nos resultados da aplicação de escalas de autonomia, interdependência e autonomia relacionada em três gerações de famílias (mães, pais, avós e filhos de ambos os sexos).

A partir disso, questionou-se o que pessoas de um contexto específico, no caso, o Rio de Janeiro, consideram como sendo autonomia. Com base em pesquisas anteriores (Seidl-de-Moura et al., 2013), trabalhou-se com a hipótese de que são pessoas com tendência a um perfil autônomo-relacionado e indagou-se sobre suas concepções de autonomia e se variavam com a idade. Não foram encontrados estudos na literatura sobre essa questão e supôs-se que as concepções de tendências universais nas tarefas do desenvolvimento de Greenfield et al. (2003) e a de ciclo vital de Erikson (Erikson, 1977; E. Erikson \& Erikson, 1997) pudessem servir de guia para analisar as possíveis variações.

Greenfield et al. (2003) discutem o equilíbrio entre autonomia e relação como a tarefa desenvolvimental central dos indivíduos a partir da adolescência. Consideram esse momento do desenvolvimento como o período de redefinição dos limites do controle parental, das obrigações familiares e do aumento das responsabilidades relativas ao comportamento social. No entanto, as demais tarefas que precedem a adolescência, no referido modelo, também podem ter relação com o desenvolvimento da mesma. A formação de relacionamentos e a aquisição de conhecimentos, tarefas relativas respectivamente à primeira infância e à infância, seguem trajetórias que dialogam com as características ecoculturais dos seus contextos de desenvolvimento. Formar relacionamentos (primeira infância), adquirir conhecimentos (infância) e equilibrar autonomia e relação (adolescência) são consideradas tarefas universais da espécie humana. Contudo, a forma como serão desenvolvidas guarda íntima relação com a ênfase dos valores de independência e interdependência no contexto social mais amplo. Além disso, é possível pensar que a ideia que pessoas de diferentes idades de um contexto específico tem sobre elas pode variar.

O modelo de Erikson de 1977 (E. Erikson \& Erikson, 1997), por sua vez, propõe o desenvolvimento como um processo contínuo, com diversas fases cruciais e a construção da identidade se dando ao longo do ciclo vital, sendo que o modelo original foi revisto na publicação de 1997. J. Erikson, esposa de Erik, no prefácio da edição de 1997, fez uma consideração que se articula com as reflexões aqui propostas a respeito da autonomia relacionada: " $E$ no presente que vivemos e circulamos e compartilhamos a Terra uns com os outros. Sem contato não há crescimento, na verdade, sem contato, a vida não é possível. Independência é uma falácia" (p.8).

Essa construção da identidade ocorre pelo equilíbrio dinâmico entre oito antíteses de desen- 
volvimento ou elementos sintônicos e distônicos, dos quais emergem qualidades psicossociais: esperança, determinação, propósito, competência, fidelidade, amor, cuidado e sabedoria. As oito duplas de antíteses são: confiança/desconfiança, autonomia/dúvida e vergonha, iniciativa/culpa, produtividade/inferioridade, identidade/confusão de identidade, intimidade/isolamento, geratividade/ estagnação, integridade/desespero, que favorecem a transição para os estágios psicossociais. Na obra de 1997, J. Erikson ainda acrescenta um novo estágio ao final do ciclo da vida, entretanto só serão retomados aqueles que dizem respeito às fases priorizadas para este estudo.

Dessa forma, a quarta fase ou quarto conflito a ser superado se dá, para Erikson (1977), entre produtividade e inferioridade, característico do período de seis a 12 anos. Para esse autor, nessa fase a criança começa a aprender habilidades importantes para integrar-se na sociedade que, em contextos urbanos escolarizados, são a leitura, a escrita e a habilidade para relacionar-se com outras pessoas. Começa a ter um sentido de produtividade e um sentimento de competência. Quando essa etapa não é adequadamente superada, a criança tem a sensação de inferioridade e incompetência. $\mathrm{Na}$ adolescência, o conflito é entre identidade e confusão de papéis. É o momento em que a pessoa aprende que tem características comuns a outros e algumas só suas, tornando-se consciente dos ajustamentos pessoais, ocupacionais, sexuais e ideológicos - os quais serão exigidos dele. A essa fase segue-se a sexta, do adulto jovem (25 a 39 anos), do conflito entre intimidade e isolamento.

Para Erikson (1977), a identidade é um pré-requisito para a intimidade. Por isso, a intimidade só é possível quando a identidade é definida, e isto ocorre na idade adulta. Essa intimidade é equilibrada pela capacidade de isolamento. A sétima fase é do contraste entre geratividade $x$ estagnação, a da maturidade - idade adulta intermediária (40 a 65 anos). É a etapa do indivíduo que tem uma ocupação e está integrado ao mercado de trabalho, além de já ser capaz de desenvolver relacionamentos íntimos. A estagnação seria a contrapartida negativa da generatividade. Finalmente, a última etapa no modelo inicial é a de integridade $x$ desesperança, da velhice (acima de 65 anos). Nesse indivíduo, pode predominar um sentimento de desesperança (o velho como um fraco, doente, sem capacidade de produzir). Em contraste, se a pessoa é capaz de acreditar que já passou por crises anteriores e as enfrentou com razoável sucesso, se pode crer que seu destino é único e válido, então pode predominar o sentimento de integridade. A velhice proporciona, assim, uma forma definitiva de identidade, na qual o indivíduo pode determinar o quanto ele foi bem sucedido em sua vida e lutar para dar um sentido a todo o seu passado, tendo em vista que espera pouco do futuro. Machado e Bandeira (2012), em uma revisão sobre o Bem-Estar Psicológico (BEP), atentam para sua relação com aspectos desenvolvimentais, psicossociais e sociodemográficos da vida dos sujeitos. Os autores sugerem que, com o avançar da idade, as pessoas ficam mais confiantes em suas crenças e experiências pessoais, manejando melhor o ambiente em função de suas necessidades, contribuindo com o aumento do BEP.

Esse modelo de Erikson (1977), junto com a proposta de Greenfield et al. (2003), sugerem que as necessidades ou as tarefas de desenvolvimento das diversas idades são diferentes. A forma como vivenciam autonomia é distinta e, em conseguinte, sua concepção sobre o termo pode variar. A partir desses pressupostos teóricos, pretende-se contribuir para a compreensão da noção de autonomia, a forma como é vista culturalmente em um contexto específico de moradores do Rio de Janeiro e sua possível relação com a idade dos participantes. Assim, o objetivo deste trabalho é analisar as crenças e concepções de crianças, adolescentes, jovens e adultos sobre autonomia e as diferenças entre as faixas etárias.

\section{Método}

Este estudo faz parte de uma pesquisa ampla, intitulada "Autonomia e Interdependência em famílias do Rio de Janeiro", que incluiu três estudos. Nela foram estudadas crenças de diferentes cuidadoras de crianças até um ano de idade e sua valorização de autonomia e relação, bem como de três 
gerações de famílias da região metropolitana do Rio de Janeiro.

\section{Participantes}

Participaram 110 sujeitos que se encontravam nas seguintes faixas etárias: final da infância e início da adolescência, entre 10 e 13 anos de idade $(n=20,18,18 \%)$; adolescentes entre 15 e 18 anos $(n=31,28,18 \%)$; jovens e adultos entre 20 e 50 anos ( $\mathrm{n}=31,28,18 \%)$; e adultos acima dos 50 ( $n=28,25,45 \%)$. Os participantes eram residentes de diferentes bairros da região metropolitana do Rio de Janeiro, com distintos níveis de escolaridade e de ambos os sexos. A Tabela 1 apresenta a distribuição dos participantes por faixa etária e níveis de escolaridade.

\section{Instrumentos}

Foi utilizado um Questionário de dados sociodemográficos com informações sobre idade, escolaridade e o local de criação dos participantes. A seguinte instrução foi dada aos participantes: "Diga cinco palavras que lhe vêm à mente quando pensa em autonomia". O participante listava, livremente, até cinco palavras ou expressões, as quais eram registradas por escrito pelo entrevistador ou pelo próprio participante na ordem em que eram evocadas. O presente estudo foi desenvolvido com dados do projeto Autonomia e Interdependên- cia em famílias do Rio de Janeiro, o qual foi submetido ao Comitê de Ética da Universidade do Estado do Rio de Janeiro e aprovado sob o Protocolo $\mathrm{n}^{\circ}$ 010.3.2010.

\section{Procedimentos}

Os participantes assinaram o Termo de Consentimento Livre e Esclarecido (TCLE) e, para aqueles com idade inferior a 18 anos, foi solicitada a autorização dos pais ou responsáveis legais, sinalizada por sua assinatura no TCLE. A aplicação do questionário completo da pesquisa com cada participante durou entre 20 e 40 minutos. Todos foram entrevistados individualmente em local conveniente e alguns preencheram dados sozinhos depois de receberem as instruções. As respostas do questionário de dados sociodemográficos foram submetidas à análise estatística descritiva, sendo calculadas as frequências absolutas e relativas.

As respostas da entrevista foram transcritas na ordem de sua evocação e submetidas a três principais etapas de análise:

\section{Etapa I - Preparação do material}

Transcritas em papel no momento da entrevista, as respostas foram, posteriormente, digitadas em tabelas no software Excel em diferentes blocos para cada faixa etária, respeitando a ordem de evocação.

Tabela 1

Distribuição dos participantes por escolaridade e faixa etária. Rio de Janeiro (RJ), 2015

\begin{tabular}{|c|c|c|c|c|c|c|c|c|c|c|}
\hline \multirow{3}{*}{ Escolaridade } & \multicolumn{8}{|c|}{ Faixa etária } & \multirow{2}{*}{\multicolumn{2}{|c|}{$\begin{array}{l}\text { Total nível de } \\
\text { escolaridade }\end{array}$}} \\
\hline & \multicolumn{2}{|c|}{ 10/13 anos } & \multicolumn{2}{|c|}{$15 / 18$ anos } & \multicolumn{2}{|c|}{ 20/50 anos } & \multicolumn{2}{|c|}{$>50$ anos } & & \\
\hline & $\mathrm{n}$ & $\%$ & $n$ & $\%$ & $n$ & $\%$ & $n$ & $\%$ & $\mathrm{n}$ & $\%$ \\
\hline Fundamental incompleto & 20 & 100,00 & 7 & 22,58 & - & - & 1 & 3,57 & 28 & 25,45 \\
\hline Fundamental completo & - & - & 1 & 3,23 & - & - & 3 & 10,71 & 4 & 3,64 \\
\hline Médio incompleto & - & - & 10 & 32,26 & 2 & 6,45 & 1 & 3,57 & 13 & 11,82 \\
\hline Médio completo & - & - & 7 & 22,58 & 3 & 9,68 & 7 & 25,00 & 17 & 15,45 \\
\hline Superior incompleto & - & - & 6 & 19,35 & 13 & 41,94 & 2 & 7,14 & 21 & 19,09 \\
\hline Superior completo & - & - & 0 & - & 8 & 25,81 & 8 & 28,57 & 16 & 14,55 \\
\hline Pós-graduação & - & - & 0 & - & 5 & 16,13 & 6 & 21,43 & 11 & 10,00 \\
\hline Total faixa etária & 20 & & 31 & & 31 & & 28 & & 110 & 100,00 \\
\hline
\end{tabular}


Etapa II - Análise de conteúdo das entrevistas

As evocações dos participantes foram submetidas à técnica de Análise de Conteúdo Temático-Categorial. Em virtude das particularidades da entrevista realizada, houve necessidade de algumas adaptações no modelo proposto por Oliveira (2008) para o desenvolvimento de sistemas de categorias, de forma que os seguintes passos foram seguidos:

1) Pré-análise: as análises preliminares envolveram o levantamento da relação de palavras emitidas em cada faixa etária e a eliminação das repetições, verificando-se o número de palavras diferentes.

2) Identificação de temas: as palavras foram organizadas pelos autores em grupos temáticos. Divididos em duplas, cada par trabalhou separadamente com o corpus de evocações de cada faixa etária, associando as palavras aos grupos temáticos e depois submetendo essa classificação ao consenso de todo o grupo. Eventuais discordâncias foram discutidas e solucionadas à luz das reflexões teóricas apresentadas na introdução. Visou-se uma análise dos dados de teor objetivo e de fácil interpretação, para que o conteúdo real das concepções de autonomia dos participantes fosse respeitado.

3) Construção das categorias: as classificações foram discutidas, chegando-se a uma distribuição consensual e a um conjunto de categorias.

4) Para cada categoria, um dos autores fez uma definição operacional propositiva e, posteriormente, as definições de todas as categorias foram apreciadas, coletivamente, pelos autores reunidos. Eventuais necessidades de ajuste foram realizadas e acordadas, chegando-se às definições que se seguem (categorias, suas definições e a lista de palavras associadas a cada categoria):

- Agência: comportamento de agir e tomar decisões por conta própria, com base em suas crenças e ideias. Diligência. A agência não implica uma dimensão moral específica, apenas o movimento de intervir no mundo. Distingue-se de independência, que seria a capacidade de ser um agente. Palavras: atitude; autoafirmação; autodefesa; autogestão; autoridade; autoridade pessoal; controle; decisão; deliberação; decidir; direciona; escolha; escolher; gestão; governar; iniciativa; liderança; lidera; poder de decisão; posicionamento; tomada de decisões; ter opinião própria $(N=22)$.

- Autorrealização: desenvolvimento de qualidades pessoais e sensação de realização como pessoa. Noção de crescimento individual e amadurecimento psicológico. Indivíduo autoconfiante, realizado, que valoriza a si mesmo e é capaz de vivenciar suas emoções de forma madura. Palavras: autoestima; autoconfiança; autorreconhecimento; amadurecimento; autorrealização; confiança; crescimento pessoal; experiência; maturidade; e reconhecimento $(N=10)$.

- Bem-estar pessoal: estado de sentir-se bem física e psicologicamente. Sensação ou sentimento de estar saudável, divertir-se, ter prazer, ter sentimentos positivos e/ou expressá-los. Satisfação com a vida em geral; com todo um domínio da vida (ex: casamento) ou com determinados aspectos de um domínio. Palavras: alegria; conforto; despreocupação; diversão; esperança; felicidade; feliz; lazer; satisfação; saúde; serenidade; sossego $(N=12)$.

- Desempenho intelectual e acadêmico: demonstração da capacidade intelectual, habilidades e conhecimento sobre um tópico, em geral, através da educação. Formação das faculdades cognitivas. Forma de conhecer o mundo. Pode incluir a satisfação com esse processo ou o atingimento de metas (e.g., terminar a faculdade). Palavras: conhecimento; educação; educação formal; estudo; estudar; faculdade; gosta de ler; intelectual; inteligente; instrução $(N=9)$.

- Distância interpessoal: percepção de não proximidade ou ligação com o outro sem implicar indiferença e não necessariamente com caráter negativo. Palavras: desvinculação; sem vínculo; sozinho(a); solitário; solidão $(N=5)$.

- Independência: capacidade de cuidar de si, de gerir sua vida, de ser responsável pelos seus atos, de não se submeter aos outros. Ausência de dependência. Difere de agência que se refere ao aspecto comportamental. Não se confunde com 
senso de liberdade, que focaliza ausência de restrições para pensar e agir. Também não significa distância ou indiferença em relação aos outros. Palavras: autossuficiente; autossuficiência; autossustentar-se; cuidar de si mesmo; emancipação; independência; independente; ser independente; leis próprias; me cuidar; morar sozinho; não depender de ninguém; pensar por si; por conta própria; reger-se; vontade própria $(\mathrm{N}=16)$.

- Realização profissional e financeira: estado de realização na profissão, na carreira e/ou financeiramente, incluindo posições, títulos obtidos, bens e serviços desejados/adquiridos. Palavras: carro; cartão de crédito; casa; casa própria; conquista; construção; conta; contas; conta bancária; dinheiro; dono do próprio dinheiro; emprego; empresa; empresário; estabilidade financeira; estabilidade; fazer compras; financeiro; ganhar dinheiro; imóvel; independência financeira; negócios; ostentação; pagamentos; poder comprar o que eu quero; poder gastar o meu; profissão; profissional; própria empresa; salário; ser advogado; ser rica; sustento; ter meu dinheiro; trabalhar; trabalho; trabalho por conta própria; vida financeira $(N=39)$.

- Senso de dever e valores: sentimento de compromisso com regras e regulações sociais. Comportamento de atender às expectativas sociais e aos compromissos com os outros. Comportamentos e valores morais, incluindo integridade pessoal. Palavras: compreensão; comprometimento; compromisso; consciência; credibilidade; cuidado; dedicação; democracia; dever; deveres; dignidade; honestidade; honradez; obrigações; regras; responsabilidade; responsável; sinceridade; valores $(N=18)$.

- Senso de liberdade: sentimento de possibilidade de agir segundo os seus desejos; ausência de limitações e restrições no pensar e no agir; não se confunde com independência, que se refere à capacidade de cuidar de si. Palavras: fazer o que quer; fazer o que quiser; fazer o que vem à cabeça; impulso; liberdade; livre; livre arbítrio; não dar satisfação a ninguém; sair sem dar satisfação; sem dar satisfação; sem patrão; vontade de fazer o que quiser na hora que quiser; viajar; viagem; viagem pelo Brasil inteiro $(N=15)$.
- Tenacidade: característica, qualidade ou estado do que é tenaz; particularidade do que demonstra perseverança; obstinação no agir. Palavras: batalhador; confiança; determinação; esforçado; firmeza; força; forte; guerreiro; resistência $(N=9)$.

- Outros: a resposta não se aplica a nenhuma das definições de categoria estabelecidas. Algumas palavras: medo; dançar; criação; locomoção; verdade; vida; isenção; família; alto; união.

De posse das categorias e definições, o corpus de evocações dos participantes foi submetido a um juiz para que analisasse as categorias e a codificação com base no material fornecido. Suas observações foram discutidas pelo grupo, ensejando a revisão das definições das categorias e a classificação das palavras emitidas por faixa etária.

\section{Etapa III - Tabulação e análise estatística dos dados}

Os dados foram analisados buscando-se verificar diferenças nas faixas etárias. A ordem de evocação das palavras foi levada em conta para as análises descritivas. A fim de analisar as categorias criadas com base nas verbalizações dos participantes em termos de frequências e possibilitar análises estatísticas inferenciais, os dados foram tabulados no software Statistical Package for the Social Sciences for Windows (versão 21).

Com base na análise de conteúdo temático-categorial das respostas, cada palavra foi considerada como uma unidade de registro e codificada para a sua categoria adequada. O total de evocações de palavras referente a cada categoria foi comparado entre as faixas etárias por meio da análise de Poisson inflacionada de zeros (ZIP), um modelo adequado para dados de contagem em que há um excesso deste número. A escolha do método partiu da necessidade de respeitar a distribuição original dos dados, na qual havia, devido às concentrações mais intensas das respostas em certas categorias, uma grande quantidade de células zeradas nas categorias restantes. Dessa maneira, o método ZIP ajusta um modelo de regressão para a 
parte dos dados em que há contagem, possibilitando a análise da variância frente às variáveis independentes utilizadas, nesse caso, a faixa etária.

\section{Resultados e Discussão}

Um total de 209 palavras/expressões diferentes foram emitidas, sendo cada uma delas classificada de acordo com as categorias propostas ou na categoria "outros". Chama atenção a variedade de palavras evocadas para se referir a "uma pessoa autônoma". Os participantes na faixa etária de 15 a 18 anos foram os que disseram mais palavras em resposta à pergunta feita, com um total de 139 evocações diferentes. Os maiores de 50 anos apresentaram o menor número, totalizando 76. Nos demais grupos, os resultados indicaram 95 evocações diferentes para os que se encontravam na faixa de 10-13 anos e 89 para os que estavam na faixa de 20-50 anos.

A análise que resultou nas 10 categorias (apresentadas no item anterior) aponta para a diversidade de possíveis significações que a palavra "autonomia" tem para os participantes. As categorias representam processos, comportamentos, sentimentos, características e estados, revelando considerável diversidade semântica.

Considerando-se o grupo total de participantes, as categorias em que houve maior frequência de emissão em primeiro lugar foram: Independência (26,61\% dos participantes) e Senso de liberdade (27,52\%). Estas foram as únicas presentes em todas as faixas etárias e também foram as mais frequentes em segundo lugar na evocação dos participantes, considerando a amostra como um todo. Isso indica uma constância de concepção ao longo das idades estudadas, embora os modelos utilizados para orientar a análise proponham tarefas diversas ao longo das mesmas.

O teste Qui-quadrado de homogeneidade indicou que não houve aleatoriedade nas respostas, ou seja, a frequência das palavras evocadas não foi homogênea entre as categorias. Isso ocorreu nos conjuntos de categorias evocadas em primeiro $\left(\chi^{2}{ }_{10}=113,29 ; p<0,05\right)$, segundo $\left(\chi^{2}{ }_{10}=84,11\right.$; $\left.\chi_{10}^{2}=51,75 ; p<0,05\right)$ e quinto lugares $\left(\chi_{9}^{2}=66,92\right.$; $p<0,05)$. Existe uma diferença significativa na proporção de respostas entre elas.

O resultado obtido reforça a ideia de que as pessoas têm concepções definidas e consistentes a respeito da autonomia, semanticamente próximas entre si, como um núcleo de conceitos socialmente compartilhados entre os indivíduos. Aparentemente, as categorias Independência e Senso de liberdade foram o cerne das concepções de uma pessoa autônoma no grupo de participantes investigados e apresentam certa estabilidade nas diferentes faixas etárias. Assim, pode-se pensar em uma noção de pessoa autônoma para o grupo, independentemente da idade, como alguém que tem a capacidade de gerir sua vida e não tem limitações ou restrições em seu pensar e agir.

A Tabela 2 apresenta a distribuição das categorias de maior frequência nas diferentes faixas etárias de acordo com a sua ordem de evocação. Observando-se essa tabela, verifica-se que a noção de autonomia explicitada pelos participantes apresenta algumas nuances de acordo com a faixa etária. Entre 10 e 13 anos de idade, por exemplo, Independência e Realização profissional e financeira empataram como categoria mais evocada em primeiro lugar (ambas com 30\% das respostas). Ou seja, a capacidade de cuidar de si vem acompanhada da realização na profissão, na carreira e/ou financeiramente.

Para Greenfield et al. (2003), a tarefa da infância é de adquirir conhecimentos e é fortemente influenciada pelos valores de independência e interdependência no contexto social mais amplo. Para Erikson (1977), seria a fase da resolução do conflito entre produtividade e inferioridade. A criança necessita aprender habilidades para integrar-se na sociedade. Em contextos urbanos escolarizados isso inclui habilidades acadêmicas e a de relacionar-se com outras pessoas. Há um sentido de produtividade e um sentimento de competência. Dentro dessa perspectiva, seria de esperar que a categoria Desempenho intelectual e acadêmico fosse a mais evocada, o que não aconteceu.

Na faixa seguinte, de 15 a 18 anos, Independência empatou em primeiro lugar com Senso 
Tabela 2

Distribuição das categorias emitidas. Rio de Janeiro (RJ), 2015

\begin{tabular}{|c|c|c|c|c|c|}
\hline Faixa etária & $1^{\circ}$ lugar & $2^{\circ}$ lugar & $3^{\circ}$ lugar & $4^{\circ}$ lugar & $5^{\circ}$ lugar \\
\hline 10 a 13 anos & $\begin{array}{l}\text { Independência }(30,00 \%) \\
\text { Realização profissional } \\
\text { e financeira }(30,00 \%)\end{array}$ & $\begin{array}{l}\text { Realização profissional } \\
\text { e financeira }(25,00 \%) \\
\text { Outros }(25,00 \%)\end{array}$ & Outros $(45,00 \%)$ & Outros $(47,34 \%)$ & $\begin{array}{l}\text { Independência }(25,00 \%) \\
\text { Outros }(25,00 \%)\end{array}$ \\
\hline 15 a 18 anos & $\begin{array}{l}\text { Independência }(23,33 \%) \\
\text { Senso de liberdade } \\
(23,33 \%)\end{array}$ & Independência (37,93\%) & $\begin{array}{l}\text { Outros }(25,00 \%) \\
\text { Realização profissional e } \\
\text { financeira }(25,00 \%)\end{array}$ & Outros $(29,63 \%)$ & Outros $(33,33 \%)$ \\
\hline 20 a 50 anos & $\begin{array}{l}\text { Senso de liberdade } \\
(38,71 \%)\end{array}$ & $\begin{array}{l}\text { Senso de liberdade } \\
(25,81 \%)\end{array}$ & Outros $(23,33 \%)$ & $\begin{array}{l}\text { Realização profissional } \\
\text { e financeira }(26,67 \%)\end{array}$ & $\begin{array}{l}\text { Realização profissional } \\
\text { e financeira }(30,00 \%) \\
\text { Outros }(30,00 \%)\end{array}$ \\
\hline$\geq 50$ anos & $\begin{array}{l}\text { Senso de Liberdade } \\
(32,14 \%)\end{array}$ & $\begin{array}{l}\text { Senso de liberdade } \\
(33,33 \%)\end{array}$ & $\begin{array}{l}\text { Senso de dever e } \\
\text { valores }(22,22 \%)\end{array}$ & $\begin{array}{l}\text { Senso de dever e } \\
\text { valores }(18,52 \%)\end{array}$ & Outros $(34,62 \%)$ \\
\hline Amostra geral & $\begin{array}{l}\text { Senso de liberdade } \\
(27,52 \%)\end{array}$ & Independência (26,36\%) & Outros $(25,71 \%)$ & Outros $(25,24 \%)$ & Outros $(31,25 \%)$ \\
\hline
\end{tabular}

de liberdade (23,33\%). Para os participantes de 20 a 50 anos, a categoria mais citada foi Senso de liberdade (38,71\%). Entre aqueles com mais de 50 anos, foi encontrado o mesmo padrão de resposta, tendo Senso de liberdade uma frequência de citação de 32,14\%. Nessas três faixas, a tendência é a mesma, mas há variação na ênfase dada ao senso de liberdade e à independência. Esses resultados não são condizentes com aqueles referentes à trajetória mais frequente em contextos brasileiros, onde é possível encontrar uma dinâmica entre autonomia e relação/interdependência (Seidl-de-Moura et al., 2013). A ideia de autonomia prevalente nesse grupo de idades variadas é de independência, de ser livre.

Quanto à categoria mais evocada em segundo lugar, na faixa etária de 10 a 13 anos foi Realização profissional e financeira e Outros. Na faixa etária seguinte, de 15 a 18 anos, Independência foi novamente a categoria mais evocada. Entre aqueles com mais de 20 anos (faixas de 20 a 50 anos e acima de 50 anos), Senso de liberdade foi novamente a categoria mais citada. O que esses resultados indicam é que, em linhas gerais, não parece haver relação entre as tarefas de desenvolvimento propostas por Erikson (1977) e Greenfield et al. (2003) para as diferentes idades e suas concepções de autonomia. O núcleo das concepções é comum.

As análises ZIP, no entanto, apontaram diferenças entre as faixas etárias em algumas categorias.
Nas categorias Agência, Distância interpessoal, Independência e Senso de liberdade, não foi encontrado efeito significativo da idade. A categoria Autorrealização teve muito baixa evocação entre os sujeitos, não sendo possível realizar a análise.

O maior percentual de participantes a evocar palavras associadas à categoria Bem-estar pessoal pertencia à faixa etária acima de 50 anos, seguidos pelos participantes de 20 a 50 anos e pelos de 10 a 13. Em comparação com os adolescentes e jovens entre 15 e 18 anos, os participantes acima de 50 também evocaram com frequência significativamente maior a categoria Bem-estar pessoal $(\beta=2,55, p<0,05)$. Esse resultado sugere que a noção de autonomia como bem-estar pessoal cresce ao longo da ontogênese, atingindo o ápice de sua valorização após os 50 anos de idade. Para Erikson (1977), depois dos 65 anos, os indivíduos que superaram com sucesso os conflitos anteriores têm um sentimento de integridade e esperança. Dessa maneira, pode-se pensar que a concepção de autonomia relacionada à categoria Bem-estar pessoal tem relação com essa tendência. Este achado corrobora a sugestão de Machado e Bandeira (2012) sobre a relação entre o aumento da idade e a consequente experiência pessoal e manejo do ambiente para maior Bem-Estar Psicológico.

Outra categoria que teve maior frequência de evocação entre os participantes mais velhos é Senso de dever e valores. A diferença foi significativa 
na comparação entre as faixas etárias de 10 a 13 anos e acima de 50 anos $(\beta=0,92, p<0,05)$. Ser autônomo não exime os indivíduos mais velhos de pensar em suas responsabilidades com os outros. Aqui foi possível encontrar a manifestação da autonomia relacionada, hipotetizada anteriormente, como característica desse grupo.

A noção de autonomia como Desempenho acadêmico e intelectual também parece se desenvolver com a idade e atinge o seu máximo de valorização entre os participantes na faixa dos 20 aos 50 anos. No entanto, decai a partir dessa idade, o que parece condizente com o momento do ciclo vital em que a ênfase não estaria mais nesse tipo de motivação. Entre os sujeitos acima dos 50 anos que participaram deste estudo, houve um menor percentual de evocação. A diferença foi estatisticamente significativa na comparação das faixas 15 a 18 anos e 20 a 50 anos $(\beta=2,20, p<0,05)$.

Os participantes com idade superior a 50 anos também pareceram associar pouco a noção de autonomia com palavras relativas à categoria Realização profissional e financeira. Estes tiveram frequência significativamente mais baixa do que as crianças e adolescentes entre 10 e 13 anos $(\beta=1,24$, $p<0,05)$, do que os adolescentes e jovens entre 15 e 18 anos $(\beta=0,95, p<0,05)$ e do que os jovens e adultos da faixa de 20 a 50 anos $(\beta=0,99, p<0,05)$. Pode-se pensar que os participantes com mais de 50 anos estariam no final da etapa da maturidade - idade adulta intermediária (40 a 65 anos) -, que contrasta geratividade $x$ estagnação, ou seja, já integrados ao mercado de trabalho e capazes de estabelecer relações (Erikson, 1977). Desse modo, a realização profissional ou financeira já estaria definida para eles.

Palavras relacionadas à Tenacidade foram evocadas com maior frequência nas respostas dos participantes com idades entre 20 e 50 anos, em comparação com a faixa de 10 a 13 anos $(\beta=-2,53$, $p<0,05)$ e acima de 50 anos $(\beta=-1,97, p<0,05)$. Especula-se que essa capacidade faça parte do conjunto de expectativas que se tem em relação aos adultos, ao menos os de um meio sociocultural como o contemplado nesta pesquisa, frente aos desafios e metas próprios de sociedades urbanas no mundo moderno.

\section{Considerações Finais}

Este estudo propôs investigar a noção de autonomia de pessoas de diferentes faixas etárias, variando de 10 a mais de 50 anos de idade, residentes do Rio de Janeiro, a partir da solicitação de que dissessem cinco palavras que Ihes viessem à mente quando pensavam em autonomia. A análise de conteúdo das respostas do conjunto de participantes foi a base para a formulação de categorias as quais mostraram haver considerável diversidade de significados envolvidos.

Ideias ligadas à independência e liberdade estiveram presentes em respostas de pessoas de todas as faixas etárias. Adicionalmente, diferenças significativas na proporção de respostas entre as categorias indicaram que as pessoas têm concepções definidas e consistentes a respeito da autonomia, com alguma proximidade semântica entre si.

A estratificação dos resultados em termos de percentuais de evocações por categoria e faixa etária indicou que a noção de autonomia explicitada pelos participantes apresentava algumas nuances em função da idade. Essa evidência pode ser vista como um indicativo do papel da ontogênese na concepção do conceito, visto como fruto de um processo de desenvolvimento que leva a diferenças na maneira de conceber essa noção ao longo do ciclo vital. Os dois modelos adotados para tentar entender variações nas concepções entre as diferentes faixas de idade, contudo, não se mostraram especialmente frutíferos para dar suporte a reflexões nesse sentido.

Nas respostas dadas sobre autonomia, esteve presente a categoria de relação Senso de dever e valores. Ela envolveu sentimento de compromisso com regras e regulações sociais e comportamento de atender às expectativas sociais. Isso indicaria que autonomia e relação não estão separadas. No entanto, essa categoria não teve evocações muito expressivas, com exceção da faixa de participantes acima de 50 anos. Assim, há uma indicação de uma noção de autonomia relacionada no grupo estudado, mas que não se revela tão nitidamente como nos estudos sobre crenças e práticas realizados anteriormente pelos autores do presente artigo (Seidl-de-Moura et al., 2013). 
Esta pesquisa abordou as trajetórias de socialização de um grupo de participantes do Rio de Janeiro de um ângulo que ainda não havia sido explorado: suas ideias de autonomia. Apesar de trazer alguns resultados que contribuem para a literatura sobre crenças e contexto, tem limitações a serem consideradas e superadas em estudos futuros. Além de ter poucos participantes em cada faixa etária, os dados foram obtidos por meio de uma única pergunta de evocação de palavras. Foi possível ter uma ideia da variedade de aspectos associados à autonomia por esses participantes, mas não uma análise mais sofisticada dessas concepções e de possíveis variações em diferentes grupos de idade. Constituiu também uma limitação a falta de um modelo teórico para explicar se e como essas concepções variariam com a idade. Os autores escolhidos não tinham essa pretensão e seus modelos foram utilizados apenas para uma orientação mais geral. Os autores pretendem continuar a investigar a autonomia relacionada, inclusive seus aspectos conceituais, seu desenvolvimento na ontogênese e formas de promovê-lo.

\section{Colaboradores}

Todos os autores deste manuscrito participaram de todas as etapas de sua elaboração: planejamento do estudo, coleta de dados, análises, discussão dos resultados, redação e revisão.

\section{Referências}

Carvalho, R. V. C., Seidl-de-Moura, M. L., Martins, G. D. F., \& Vieira, M. L. (2014). Culture and developmental trajectories: A discussion on contemporary theoretical models. Early Child Development and Care, 184(11), 1599-1614. https://doi.org/10.1080/03004430. 2013.871273

Erikson, E. (1977). Childhood and society. London: Paladin.

Erikson, E., \& Erikson, J. (1997). The life cycle completed. New York: Norton.

Greenfield, P. M., Keller, H., Fuligni, A., \& Maynard, A. (2003). Cultural pathways through universal development. Annual Review of Psychology, 54, 461-490. https://doi.org/10.1146/annurev.psych.54. 101601.145221
Kagitçibasi, Ç. (1996). The autonomous-relational self: A new synthesis. European Psychologist, 1(3), 180-186. https://doi.org/10.1027/1016-9040.1.3.180

Kagitçibasi, Ç. (2007). Family, self and human development across cultures. London: Lawrence Erlbaum Associates.

Kagitçibasi, Ç. (2012). Socio-cultural change and integrative syntheses in human development: Autonomousrelated self and social-cognitive competence. Child Development Perspectives, 6(1), 5-11. https://doi.org/ 10.1111/j.1750-8606.2011.00173.x

Keller, H. (2007). Cultures of infancy. Mahwah: Lawrence Erlbaum Associates.

Keller, H. (2012). Autonomy and relatedness revisited: Cultural manifestations of universal human needs. Child Development Perspectives, 6(1), 12-18. https:// doi.org/10.1111/j.1750-8606.2011.00208.x

Machado, W. L., \& Bandeira, D. R. (2012). Bem-estar psicológico: definição, avaliação e principais correlatos. Estudos de Psicologia (Campinas), 29(4), 587-595. https://doi.org/10.1590/S0103-166X2012000400 013

Moura, C. B., \& Gabassi, S. E. (1998). Dependência x autonomia infantil: o papel da psicoterapia no desenvolvimento sócio-emocional de crianças imaturas. Estudos de Psicologia (Campinas), 15(3), 71-77. https:// doi.org/10.1590/S0103-166X1998000300006

Oliveira, D. C. D. (2008). Análise de conteúdo temático-categorial: uma proposta de sistematização. Revista de Enfermagem, 16(4), 569-576.

Ramos, F. P., Enumo, S. R. F., \& Paula, K. M. P. (2015). Teoria motivacional do coping: uma proposta desenvolvimentista de análise do enfrentamento do estresse. Estudos de Psicologia (Campinas), 32(2), 269-279. https://doi.org/10.1590/0103-166X2015000200011

Seidl-de-Moura, M. L., Carvalho, R. V. C. C., \& Vieira, M. L. (2013). Brazilian mothers parenting models. In M. L. Seidl-de-Moura (Ed.), Parenting in South American and African contexts. Rijeka: InTech.

Seidl-de-Moura, M. L., \& Ribas, A. F. P. (2009). Evolução e desenvolvimento humano. In M. Yamamoto \& E. Otta (Orgs.), Psicologia evolucionista (pp.77-85). Rio de Janeiro: Guanabara Koogan.

Seidl-de-Moura, M. L., Mendes, D. M. L. F., Vieira, M. L., Korbarg, A. P., Pessôa, L. F., \& Bandeira, T. T. A. (2013). Brazilian mothers' description of their children: Dimensions of autonomy and relatedness. Psicologia: Teoria e Pesquisa, 29(3), 249-255.

Recebido: junho 2, 2015

Versão final: março 7, 2016

Aprovado: abril 8, 2016 
